\title{
Aortic Elastic Properties and Myocardial Performance Index Are Impaired in Patients with Lichen Planus
}

\author{
C. Koseoglu ${ }^{a} \quad$ M. Erdogan ${ }^{b} \quad$ A.G. Ertem ${ }^{b} \quad$ G. Koseoglu ${ }^{d} \quad$ G. Akoglu ${ }^{c}$ A. Aktas ${ }^{c}$ \\ E. Ozdemir ${ }^{b}$ O. Kurmus ${ }^{\text {e }}$ T. Durmaz ${ }^{\text {b }}$ T. Keles ${ }^{b}$ E. Bozkurt ${ }^{b}$
}

a Department of Cardiology, Ankara Training and Research Hospital, Departments of ${ }^{b}$ Cardiology and ${ }^{c}$ Dermatology, Ataturk Training and Research Hospital, and 'Department of Dermatology, Ankara University Faculty of Medicine, Ankara, and ${ }^{\text {} D e p a r t m e n t ~ o f ~ C a r d i o l o g y, ~ T a r s u s ~ S t a t e ~ H o s p i t a l, ~ M e r s i n, ~ T u r k e y ~}$

\section{Key Words}

Aortic elastic properties - Myocardial performance index .

Tei index $\cdot$ Lichen planus

\begin{abstract}
Objectives: The aim of this study was to investigate the elastic properties of the aorta and the myocardial performance index of the left ventricle (LV) in patients with lichen planus (LP). Subjects and Methods: A total of 54 patients with LP and 50 controls were enrolled in the study. The 2 groups were well-matched regarding age, gender, body mass index, any smoking history, diabetes mellitus and systolic and diastolic blood pressure (SBP and DBP). The echocardiographic examination was performed on the study subjects and the controls. Aortic elasticity parameters and the myocardial performance index of the LV were calculated. The Student $t$ test, the $x^{2}$ test and multiple linear regression were used for the statistical analysis. Results: Aortic strain (AS, $4.77 \pm 1.81$ vs. $8.95 \pm 2.22 ; p<0.001)$ and aortic distensibility (AD, $0.25 \pm$ 0.009 vs. $0.42 \pm 0.120 ; p<0.001)$ were significantly lower, and aortic stiffness index $\beta$ (ASI $\beta, 3.65 \pm 1.03$ vs. $2.70 \pm 0.91 ; p<$ 0.001 ) was significantly higher in the LP group than in the controls. The myocardial performance index (Tei index) was
\end{abstract}

significantly higher in the LP group than in the control group $(p=0.001)$. The duration of the LP was negatively correlated with AS $(r=-0.364, p<0.001)$ and $A D(r=-0.279, p=0.006)$, and positively correlated with the Tei index $(r=0.324, p=$ $0.001)$ and $A S I \beta(r=0.364, p<0.001)$. After adjustment for relevant confounders (age, male gender, smoking, SBP, DBP, diabetes mellitus and low- and high-density lipoprotein cholesterol), LP and its duration were still associated with $A S, A D$ and $A S I \beta$. Conclusion: In this study, AS and AD were lower and $A S I \beta$ and myocardial performance index higher in LP patients than in controls.

C 2015 S. Karger AG, Basel

\section{Introduction}

Lichen planus (LP) is a chronic, idiopathic, immunomediated inflammatory disease that affects the skin and mucous membranes [1]. The disease occurs in $0.4-1.9 \%$ of the population and mostly in middle-aged women [2]. The etiopathogenesis of LP is still far from being completely understood. It is accepted that LP represents a T-cell-mediated inflammatory response with an infiltrating cell population composed of both T4 and T8 lymphocytes [3].

\begin{tabular}{ll}
\hline KARGER & $\begin{array}{l}\text { C) } 2015 \text { S. Karger AG, Basel } \\
\text { 1011-7571/15/0253-0247\$39.50/0 Oper }\end{array}$ \\
$\begin{array}{l}\text { E-Mail karger@karger.com } \\
\text { www.karger.com/mpp }\end{array}$ & $\begin{array}{l}\text { This is an Open Access article licensed under the terms of the } \\
\text { Creative Commons Attribution-NonCommercial 3.0 Un- } \\
\text { ported license (CC BY-NC) (www.karger.com/OA-license), } \\
\text { applicable to the online version of the article only. Distribu- } \\
\text { tion permitted for non-commercial purposes only. }\end{array}$
\end{tabular}

Cemal Koseoglu, MD

Ankara Training and Research Hospital

Sukriye District, Ulucanlar Street

TR-06340 Altındag, Ankara (Turkey)

E-Mail drcemalkoseoglu@ hotmail.com 
Inflammation is associated with endothelial dysfunction and atherosclerosis [4]. Endothelial dysfunction, an early step in the process of atherogenesis, is commonly assessed by determining the elastic properties of the aorta: aortic strain (AS), aortic distensibility (AD) and the aortic stiffness index (ASI $\beta$ ) can all be measured noninvasively [5]. Although invasive methods are still the gold standard, it has been shown that noninvasively calculated aortic elasticity on echocardiography has an excellent correlation with invasive methods [5]. Arterial stiffness is a factor in atherosclerosis and impaired aortic elastic properties are associated with cardiovascular mortality and morbidity [6].

The myocardial performance index, also known as the Tei index, may reflect global left ventricle (LV) function better than an isolated evaluation of either LV ejection fraction or relaxation time. The mean normal value of the Tei index is $0.39 \pm 0.05$ for the LV [7]. It is an index that incorporates both systolic and diastolic time intervals in expressing global systolic and diastolic ventricular function.

Clinical and subclinical cardiovascular involvement have been reported in patients with psoriasis, which is recognized as a chronic inflammatory skin disease that displays a similar physiopathology to LP [8]. Fedele et al. [9] suggested that common oral mucosal diseases including LP were associated with increased markers of systemic inflammation and a history of cardiovascular disease. However, little is known regarding the potential association of LP with cardiovascular disease, and there is a considerable lack of evidence to demonstrate the relationship between LP, aortic elastic properties and global LV function. Therefore, in this study, the aim was to evaluate the elastic properties of the aorta and the myocardial performance index of the LV in patients with LP.

\section{Subjects and Methods}

\section{Patient Selection}

A total of 89 patients with LP and 50 age- and sex-matched controls were enrolled in this study from April 2014 to February 2015. The LP was assessed clinically in a standardized dermatological examination by experienced, trained physicians, some of whom are dermatologic consultants (G.K. and A.A.). The examination involved the whole body including the scalp and nails. LP was confirmed according to clinical assessment and histopathological examination. Exclusion criteria were: renal failure, hepatic insufficiency, a history of cardiovascular, cerebrovascular or connective-tissue disease, hypertension and the presence of epithelial dysplasia detected on histopathological examination. Thirty-three patients on systemic treatment such as steroids, immunosuppres- sion, retinoids, lipid-lowering therapy, antihypertensive or antiaggregant drugs were excluded from the study [10]. Two patients were excluded from the study because of the unavailability of laboratory data. Thus, the final number of patients included was 54 . The 2 groups, i.e. patients and controls, were well-matched regarding age, gender, body mass index (BMI), any smoking history, diabetes mellitus and systolic and diastolic blood pressure (SBP and DBP). The disease duration in the patients with LP ranged from 4 to 60 months. Thirty patients with LP had only cutaneous involvement, 19 had only mucosal lesions and 5 patients had mucocutaneous involvement. The study was approved by the Institution's Ethics Committee. Written informed consents were obtained from all participants.

\section{Clinical and Biochemical Parameters}

The height, weight and blood pressure were measured, and the BMI was calculated. Blood was collected in tripotassium EDTA tubes. Serum triglycerides, low- and high-density lipoprotein (LDL and HDL) cholesterol and glucose levels were determined in samples collected after a 12-hour fasting period. Total plasma cholesterol, triglycerides and HDL cholesterol were measured by an enzymatic colorimetric method using an autoanalyzer and reagents (Olympus AU 600, Olympus Diagnostics GmbH, Hamburg, Germany). The LDL cholesterol levels were calculated by the Friedewald formula. Blood glucose was measured by the glucose oxidase method. The blood counts were determined using a Sysmex XT-1800i hematology analyzer (Sysmex Corp., Kobe, Japan). Baseline neutrophil lymphocyte ratio (NLR) was determined by dividing neutrophil count by lymphocyte count, and baseline platelet lymphocyte ratio (PLR) was measured by dividing platelet count by lymphocyte count.

\section{Echocardiographic Examination}

The echocardiographic examination was performed at rest, with the patient in a left lateral decubitus position, using a commercially available echocardiographic device (Vivid 7, GE Medical Systems, Milwaukee, Wis., USA) with a 3-MHz transducer, by a single, experienced echocardiographer (M.E.) who was blinded to the clinical data. Using M-mode echocardiography, long-axis measurements were obtained at the level distal to the mitral valve leaflets according to the current recommendations of the American Society of Echocardiography [11]. The LV ejection fraction was calculated via a modified biplane Simpson's method from apical 4- and 2-chamber views [11]. The pulsed Doppler sampling volume was placed between the tips of the mitral valve leaflets to obtain maximum filling velocities. Parameters related to diastolic function of the LV were obtained as follows: the sample volume (size $2 \mathrm{~mm}$ ) of the pulsed-wave Doppler was placed between the tips of the mitral leaflets in the apical 4-chamber view. Early (E) and late (A) transmitral flow velocities and the ratio of early-to-late peak velocities (E/A) were obtained. Doppler echocardiograms were recorded on a strip-chart recorder with a sweep speed of 100 $\mathrm{mm} / \mathrm{s}$; the values of 3 different cardiac cycles were averaged. The diameter of the ascending aorta was measured in the parasternal long-axis view using M-mode tracing at a level of $3 \mathrm{~cm}$ above the aortic valve. Systolic aortic diameter (AoSD) was measured at the maximal anterior motion of the aorta, while diastolic aortic diameter (AoDD) was measured at the peak of the QRS complex on the simultaneously recorded electrocardiogram. Five consecutive measurements were averaged. Aortic elasticity parameters were 
Table 1. Baseline clinical and hematological characteristics of the study population

\begin{tabular}{lccc}
\hline Variables & LP patients $(\mathrm{n}=54)$ & Controls $(\mathrm{n}=50)$ & p value \\
\hline Age, years & $45.68 \pm 13.01$ & $47.29 \pm 6.88$ & 0.475 \\
Female & $32(59.3)$ & $30(60.8)$ & 0.866 \\
BMI & $28.8 \pm 4.2$ & $29.4 \pm 5.0$ & 0.518 \\
SBP, mm Hg & $126 \pm 9$ & $127 \pm 12$ & 0.262 \\
DBP, mm Hg & $79 \pm 6$ & $78 \pm 9$ & 0.577 \\
Diabetes mellitus & $10(18.5)$ & $14(29.2)$ & 0.221 \\
Smoker & $15(27.7)$ & $14(29.2)$ & 0.284 \\
Hypercholesterolemia & $22(40.7)$ & $13(26.8)$ & 0.161 \\
On topical steroid treatment & $30(55.5)$ & - & - \\
A positive family history & $17(31)$ & $8(17)$ & 0.111 \\
LDL cholesterol, mg/dl & $118.5 \pm 39.4$ & $117.4 \pm 33.7$ & 0.891 \\
HDL cholesterol, mg/dl & $42.8 \pm 10.3$ & $55.4 \pm 2.5$ & 0.005 \\
Triglycerides, mg/dl & $161 \pm 97$ & $141 \pm 82$ & 0.281 \\
Total cholesterol, mg/dl & $203 \pm 44$ & $192 \pm 36$ & 0.207 \\
Creatinine, mg/dl & $0.8 \pm 0.2$ & $1.1 \pm 0.4$ & 0.228 \\
Glucose, mg/dl & $97 \pm 30$ & $109 \pm 37$ & 0.101 \\
Hemoglobin, g/l & $11.4 \pm 3.4$ & $12.1 \pm 2.3$ & 0.475 \\
WBC count, $10^{3} / \mu \mathrm{l}$ & $7.6 \pm 1.6$ & $7.5 \pm 1.6$ & 0.772 \\
NLR & $3.1 \pm 1.3$ & $1.8 \pm 0.5$ & $<0.001$ \\
PLR & $165 \pm 31$ & $107 \pm 26$ & $<0.001$ \\
\hline
\end{tabular}

Values express the number of patients (\%) or the mean \pm SD of the variable. calculated according to the following formulae (where PP is pulse pressure) [12]:

- $\mathrm{AS}(\%)=100 \times(\mathrm{AoSD}-\mathrm{AoDD}) / \mathrm{AoDD}$.

- $\quad \mathrm{ASI} \beta=\ln (\mathrm{SBP} / \mathrm{DBP}) / \mathrm{AS}$.

- $\mathrm{AD}=2 \times(\mathrm{AoSD}-\mathrm{AoDD}) /(\mathrm{AoDD} \times \mathrm{PP})\left(\mathrm{cm}^{2} \times \mathrm{dyn}^{(-1)} \times 10^{(-6)}\right)$.

- $\mathrm{PP}=\mathrm{SBP}-\mathrm{DBP}$.

Myocardial segment velocities, i.e. peak systolic ( $\mathrm{Sm}$ ), and early and late diastolic (Em and Am) velocities, were measured via spectral-pulsed Doppler of the LV free wall from the apical 4-chamber view [11]. Tissue Doppler imaging was performed using apical 4-chamber, 2-chamber and long-axis views to determine the motions of the LV. Sample volume was located at the lateral and septal side of the mitral annulus. Em, Am and Sm mitral annulus velocities were measured. The isovolumetric relaxation time (IVRT) was defined as the interval between the end of the aortic outflow and the beginning of the mitral inflow signal. The time interval from the end of the onset of mitral annular velocity pattern during diastole, i.e. the isovolumetric contraction time (IVCT), was measured. The Tei index was calculated as [7]:

- Tei index $=($ IVCT + IVRT $) /$ ejection time

\section{Statistical Analyses}

The Kolmogorov-Smirnov test was used to evaluate normal distribution. Continuous variables were expressed as mean $\pm \mathrm{SD}$ and categorical variables were defined as number (\%). The Student $\mathrm{t}$ test was used to compare normally distributed data between groups and the Mann-Whitney $U$ test for nonnormally distributed data. The $\chi^{2}$ test was used in the investigation of categoric variables. The Pearson and Spearman analyses were used for correlation analysis. Multiple linear regression analysis after adjusting for relevant confounders (age, male gender, smoking, SBP, DBP, diabe- tes mellitus and LDL cholesterol) was performed to evaluate the relationship between aortic elastic properties, Tei index and LP. $p<0.05$ was regarded as significant. SPSS (SPSS, 17.0, Chicago, Ill., USA) was used for the statistical analyses.

\section{Results}

\section{Characteristics of Study Participants}

Demographic, clinical and biochemical parameters of patients are shown in table 1. Mean duration of LP was $20.51 \pm 11.40$ months. Hematological variables of both groups and the comparisons are also summarized in table 1. No statistical differences were found between LP and the controls except for $\operatorname{NLR}(3.1 \pm 1.3$ vs. $1.8 \pm 0.5$; $\mathrm{p}<0.001)$, PLR $(165 \pm 31$ vs. $107 \pm 26 ; \mathrm{p}<0.001)$ and HDL cholesterol ( $42.8 \pm 10.3$ vs. $55.4 \pm 2.5 \mathrm{mg} / \mathrm{dl} ; \mathrm{p}=0.005)$.

\section{Associations of LP and Echocardiographic Parameters}

The echocardiographic parameters of both groups and the comparisons are summarized in table 2. AS (4.77 \pm 1.81 vs. $8.95 \pm 2.22 ; \mathrm{p}<0.001)$ and $\mathrm{AD}(0.25 \pm 0.009$ vs. $0.42 \pm 0.120 ; \mathrm{p}<0.001)$ were significantly lower and ASI $\beta$ (3.65 \pm 1.03 vs. $2.70 \pm 0.91 ; \mathrm{p}<0.001)$ significantly higher in the LP group than in the control group. The AoSD and AoDD were significantly greater in LP patients than in 
Table 2. Echocardiographic characteristics of the study subjects and the controls

\begin{tabular}{lccr}
\hline Variables & LP patients $(\mathrm{n}=54)$ & Controls $(\mathrm{n}=50)$ & $\mathrm{p}$ value \\
\hline LV end-diastolic diameter, cm & $4.8 \pm 0.4$ & $4.6 \pm 0.3$ & 0.028 \\
LV end-systolic diameter, cm & $2.9 \pm 0.3$ & $2.8 \pm 0.2$ & 0.019 \\
LV ejection fraction, \% & $62.8 \pm 4.4$ & $62.1 \pm 5.0$ & 0.502 \\
Left atrium diameter, cm & $3.68 \pm 0.35$ & $3.51 \pm 0.36$ & 0.023 \\
İnterventricular septal thickness, cm & $0.94 \pm 0.11$ & $0.99 \pm 0.16$ & 0.082 \\
Posterior wall thickness, cm & $0.88 \pm 0.10$ & $0.91 \pm 0.14$ & 0.182 \\
E, m/s & $0.80 \pm 0.15$ & $0.66 \pm 0.14$ & $<0.001$ \\
A, m/s & $0.74 \pm 0.15$ & $0.74 \pm 0.14$ & 0.906 \\
E/A & $1.13 \pm 0.34$ & $0.93 \pm 0.32$ & 0.005 \\
Lateral Em, m/s & $0.12 \pm 0.09$ & $0.11 \pm 0.14$ & 0.619 \\
Medial Em, m/s & $0.10 \pm 0.74$ & $0.06 \pm 0.02$ & 0.010 \\
Medial E/Em & $10.47 \pm 2.60$ & $9.26 \pm 2.61$ & 0.027 \\
IVRT, ms & $83.0 \pm 11.4$ & $74.9 \pm 7.7$ & $<0.001$ \\
IVCT, ms & $55.0 \pm 3.6$ & $53.8 \pm 3.6$ & 0.121 \\
Ejection time, ms & $300 \pm 11$ & $301 \pm 15$ & 0.820 \\
Tei index & $0.45 \pm 0.04$ & $0.43 \pm 0.02$ & 0.001 \\
AoSD, cm & $3.14 \pm 0.37$ & $2.94 \pm 0.34$ & 0.003 \\
AoDD, cm & $2.97 \pm 0.38$ & $2.74 \pm 0.35$ & 0.004 \\
AS & $4.77 \pm 1.81$ & $8.95 \pm 2.22$ & $<0.001$ \\
ASI $\beta$ & $3.65 \pm 1.03$ & $2.70 \pm 0.91$ & $<0.001$ \\
AD & $0.25 \pm 0.009$ & $0.42 \pm 0.120$ & $<0.001$ \\
\hline
\end{tabular}

Values are expressed as means $\pm \mathrm{SD}$. controls. The Tei index was significantly higher in patients with LP than in control subjects $(0.45 \pm 0.04$ vs. 0.43 $\pm 0.02 ; \mathrm{p}=0.001)$. There were significant differences between the groups in terms of LV diastolic and systolic and left atrium diameters. $\mathrm{E}$ and $\mathrm{E} / \mathrm{A}$ values and medial E/Em ratio were increased in LP patients. LP duration had a positive correlation with ASI $\beta(r=0.364, p<0.001)$ and a negative correlation with $\mathrm{AS}$ and $\mathrm{AD}(\mathrm{r}=-0.364, \mathrm{p}<$ 0.001 and $\mathrm{r}=-0.279, \mathrm{p}=0.006$, respectively; table 3 ). There was a positive correlation between the Tei index and LP duration $(\mathrm{r}=0.324, \mathrm{p}=0.001)$. The Tei index was also positively correlated with SBP $(\mathrm{r}=0.246, \mathrm{p}=0.016)$, $\operatorname{DBP}(r=0.241, \mathrm{p}=0.018)$, left atrial diameter $(\mathrm{r}=0.203$, $\mathrm{p}=0.048)$ and $\mathrm{E} / \mathrm{Em}(\mathrm{r}=0.423, \mathrm{p}<0.001)$. In the multivariate analysis, after adjustments for relevant confounders (age, male gender, smoking, SBP, DBP, diabetes mellitus, LDL cholesterol and HDL cholesterol), LP and LP duration were associated with AS $(\beta=-0.370, p=0.030$ and $\beta=-0.275, \mathrm{p}=0.036$, respectively $), \mathrm{AD}(\beta=-0.443$, $\mathrm{p}=0.006$ and $\beta=-0.253, \mathrm{p}=0.047$, respectively) and ASI $\beta(\beta=0.537, p<0.001$ and $\beta=0.216, p=0.049$, respectively), but not with the Tei index $(\beta=0.289, \mathrm{p}=$ 0.090 and $\beta=0.136, p=0.272$, respectively; table 4 ).

\section{Discussion}

In our study, the aortic elasticity parameters AS and AD were significantly lower and the ASI $\beta$ and Tei index significantly higher in LP patients (who had no clinical evidence of heart disease) than in the controls. LP and its duration were associated with AS, AD and ASI $\beta$ after adjustment for relevant confounders.

The increase in arterial stiffness in this study could be due to the fact that this is a predictor of cardiovascular morbidity and mortality [6]. Inflammation and endothelial dysfunction are associated with atherosclerosis [4]. Damage to the arterial wall due to atherosclerosis increases arterial stiffness [13]. Increased aortic stiffness has been reported in several chronic inflammatory diseases such as systemic sclerosis, psoriasis, systemic vasculitis and rheumatoid arthritis [14-17]. Bicer et al. [18] reported that in psoriatic patients with no cardiac involvement, aortic elasticity was decreased and this decrease was correlated with the duration and the severity of the disease. It has been hypothesized that the association of LP with cardiovascular risk is due to chronic systemic inflammation $[9,10,19]$. Although there was no difference in terms of white blood cell (WBC) count between the 2 groups, the NLR was higher in LP patients than in controls. The 
Table 3. Correlations of aortic elasticity properties and the Tei index

\begin{tabular}{|c|c|c|c|c|c|c|c|c|}
\hline \multirow[t]{2}{*}{ Variables } & \multicolumn{2}{|l|}{ AS } & \multicolumn{2}{|l|}{$\mathrm{AD}$} & \multicolumn{2}{|l|}{ ASI $\beta$} & \multicolumn{2}{|c|}{ Tei index } \\
\hline & $\mathrm{r}$ & $\mathrm{p}$ & $\mathrm{r}$ & $\mathrm{p}$ & $\mathrm{r}$ & $\mathrm{p}$ & $\mathrm{r}$ & $\mathrm{p}$ \\
\hline Age & -0.192 & 0.063 & -0.171 & 0.097 & 0.040 & 0.690 & 0.115 & 0.269 \\
\hline Gender & -0.040 & 0.702 & -0.084 & 0.418 & 0.039 & 0.711 & 0.082 & 0.432 \\
\hline BMI & -0.062 & 0.549 & -0.086 & 0.406 & -0.104 & 0.314 & 0.106 & 0.305 \\
\hline Diabetes mellitus & 0.146 & 0.157 & 0.160 & 0.122 & -0.049 & 0.640 & -0.104 & 0.111 \\
\hline Smoker & 0.039 & 0.707 & 0.110 & 0.919 & 0.039 & 0.706 & 0.002 & 0.987 \\
\hline SBP & -0.067 & 0.519 & -0.216 & 0.035 & -0.212 & 0.039 & 0.246 & 0.016 \\
\hline DBP & 0.010 & 0.913 & 0.086 & 0.408 & -0.119 & 0.253 & 0.241 & 0.018 \\
\hline LDL cholesterol & -0.010 & 0.926 & -0.079 & 0.446 & 0.084 & 0.418 & 0.181 & 0.079 \\
\hline HDL cholesterol & 0.275 & 0.007 & 0.252 & 0.014 & -0.140 & 0.176 & -0.098 & 0.343 \\
\hline $\mathrm{LAD}$ & -0.158 & 0.127 & -0.150 & 0.147 & 0.105 & 0.312 & 0.203 & 0.048 \\
\hline LVEDD & -0.207 & 0.054 & -0.169 & 0.102 & 0.022 & 0.835 & 0.081 & 0.435 \\
\hline LVESD & 0.269 & 0.080 & -0.192 & 0.062 & 0.003 & 0.979 & 0.011 & 0.915 \\
\hline LV ejection fraction & 0.139 & 0.179 & 0.075 & 0.472 & -0.016 & 0.876 & 0.073 & 0.481 \\
\hline LP duration & -0.364 & $<0.001$ & -0.279 & 0.006 & 0.364 & $<0.001$ & 0.324 & 0.001 \\
\hline Medial E/Em & -0.150 & 0.148 & -0.070 & 0.500 & 0.062 & 0.553 & 0.423 & $<0.001$ \\
\hline
\end{tabular}

LAD = Left atrium diameter; LVEDD = LV end-diastolic diameter; LVESD = LV end-systolic diameter.

Table 4. Multivariate analysis of aortic elasticity properties and Tei index in patients with LP

\begin{tabular}{|c|c|c|c|c|c|c|c|c|}
\hline \multirow[t]{2}{*}{ Variables } & \multicolumn{2}{|l|}{ AS } & \multicolumn{2}{|l|}{$\mathrm{AD}$} & \multicolumn{2}{|l|}{ ASI $\beta$} & \multicolumn{2}{|c|}{ Tei index } \\
\hline & $\beta$ & $\mathrm{p}$ & $\beta$ & $\mathrm{p}$ & $\beta$ & $\mathrm{p}$ & $\beta$ & $\mathrm{p}$ \\
\hline LP & -0.370 & 0.030 & -0.443 & 0.006 & 0.537 & $<0.001$ & 0.289 & 0.090 \\
\hline Age & -0.147 & 0.209 & -0.382 & 0.014 & 0.211 & 0.019 & -0.060 & 0.605 \\
\hline Gender & -0.014 & 0.898 & -0.118 & 0.212 & 0.070 & 0.388 & 0.089 & 0.412 \\
\hline BMI & 0.045 & 0.713 & 0.043 & 0.694 & -0.044 & 0.641 & -0.114 & 0.333 \\
\hline Diabetes mellitus & -0.079 & 0.488 & -0.012 & 0.904 & 0.065 & 0.456 & 0.005 & 0.964 \\
\hline Smoker & -0.040 & 0.722 & -0.109 & 0.268 & 0.014 & 0.865 & 0.057 & 0.600 \\
\hline SBP & -0.166 & 0.417 & -0.186 & 0.307 & 0.246 & 0.118 & -0.054 & 0.788 \\
\hline $\mathrm{DBP}$ & -0.063 & 0.747 & -0.015 & 0.932 & 0.145 & 0.330 & 0.304 & 0.113 \\
\hline LDL cholesterol & -0.065 & 0.571 & -0.005 & 0.958 & 0.070 & 0.427 & 0.153 & 0.176 \\
\hline HDL cholesterol & 0.019 & 0.868 & 0.053 & 0.593 & -0.113 & 0.188 & 0.093 & 0.409 \\
\hline LAD & 0.006 & 0.958 & 0.013 & 0.896 & -0.020 & 0.814 & 0.131 & 0.246 \\
\hline Ejection fraction & -0.029 & 0.781 & -0.055 & 0.555 & 0.097 & 0.226 & 0.081 & 0.444 \\
\hline LP duration & -0.275 & 0.036 & -0.253 & 0.047 & 0.216 & 0.049 & 0.136 & 0.277 \\
\hline
\end{tabular}

$\mathrm{LAD}=$ Left atrium diameter.

WBC subtypes may have reflected different aspects of inflammation, and NLR was accepted as a marker of systemic inflammation [20]. Fedele et al. [9] showed that common oral mucosal diseases to be independently associated with raised markers of systemic inflammation and a history of cardiovascular disease. Saleh et al. [19] demonstrated that patients with LP had higher markers of both metabolic and cardiovascular risk factors in rela- tion to controls due to long-standing inflammation. It is plausible that cell-mediated immune dysfunction is implicated in LP etiology and pathophysiology. Antigens are processed by Langerhans cells and then presented to $\mathrm{T}$ lymphocytes. The stimulated T lymphocytes attack keratinocytes. The greater number of cytokines released by the wounded keratinocytes induces a further release of cytokines and chemokines belonging to either the Th1 or 
Th2 cell groups [21]. It was found by Simark-Mattsson et al. [22] that there are elevated serum levels of interleukin (IL)-2, IL-6, IL-10, TNF- $\alpha$ and TGF- $\beta$ within the subepithelial infiltrate in patients with LP. In patients with ankylosing spondylitis, increased levels of TNF- $\alpha$, IL-2 and IL-6 have been reported. These cytokines produce metalloproteinases that degrade the collagen and elastin content of the aortic intima, so they may contribute to increased aortic stiffness [23].

In this study, the global myocardial function, represented as the Tei index, was impaired in LP patients beside the impairment of aortic elasticity. The increased aortic stiffness could also increase afterload and induce myocardial structural changes that lead to an increase in systolic and diastolic myocardial stiffness [24]. This increased myocardial stiffness and structural changes cause gradual impairment, beginning with diastolic dysfunction and progressing to systolic dysfunction $[6,24]$. The Tei index is conventionally used as a measure of combined systolic and diastolic function [7]. Measuring it is simple and reproducible, and it is independent of heart rate, blood pressure and gender [7, 25, 26]. It has been shown to be a safer parameter for the evaluation of systolic and diastolic function than standard echocardiographic indices [7].

Arterial stiffness is associated with atherosclerosis at various sites in the arterial tree, and dyslipidemia is a risk factor for atherosclerosis [27]. In our study, LDL cholesterol levels were similar in the 2 groups, but HDL cholesterol was significantly lower in LP patients than in controls. Previous studies demonstrate a relationship between dyslipidemia and LP [28]. Arias-Santiago et al. [29] showed an association between LP and dyslipidemia, and suggested that screening lipid levels may be useful to detect individuals at risk and then begin preventive treatment towards improving the cardiovascular disease. López-Jornet et al. [30] demonstrated a higher atherogenic index and lower HDL cholesterol among oral LP patients.

The major limitations of this study were the small study population and the lack of a long-term clinical follow-up. As the characteristics of the patients were limited by the randomization criteria, our results cannot apply to LP patients in general. Further studies with larger sample sizes are necessary to evaluate the association between LP and cardiovascular risk. WBC count, NLR and PLR were used as markers of inflammation, but examining the role of C-reactive protein would strengthen the case for inflammation in LP as well as the impaired aortic elastic properties and myocardial performance index.

\section{Conclusion}

In this study, the aortic elastic properties and myocardial performance index were found to be impaired in patients with LP. The duration of LP was correlated with aortic elastic functions. Further large controlled studies are required to validate our results.

\section{Disclosure Statement}

There were no conflicts of interest.

\section{References}

1 Arias-Santiago S, Buendia-Eisman A, Aneiros-Fernandez J, et al: Lipid levels in patients with lichen planus: a case-control study. J Eur Acad Dermatol Venereol 2011;25:1398-1401.

2 Manolache L, Seceleanu-Petrescu D, Benea V: Lichen planus patients and stressful events. J Eur Acad Dermatol Venereol 2008;22:437441.

-3 van der Waal I: Oral lichen planus and oral lichenoid lesions; a critical appraisal with emphasis on the diagnostic aspects. Med Oral Patol Oral Cir Bucal 2009;14:310-314.

4 Balta S, Cakar M, Demirkol S, et al: Arterial stiffness itself without other inflammatory markers may not provide information to clinicians. J Clin Hypertens 2013;15:303.
5 Stefanadis C, Stratos C, Boudoulas H, et al: Distensibility of the ascending aorta: comparison of invasive and non-invasive techniques in healthy men and in men with coronary artery disease. Eur Heart J 1990;11:990-996.

6 Eren M, Gorgulu S, Uslu N, et al: Relation between aortic stiffness and left ventricular diastolic function in patients with hypertension, diabetes, or both. Heart 2004;90:37-43.

$\checkmark 7$ Tei C, Ling LH, Hodge DO, et al: New index of combined systolic and diastolic myocardial performance: a simple and reproducible measure of cardiac function - a study in normals and dilated cardiomyopathy. J Cardiol 1995; 26:357-566.

8 Rocha-Pereira P, Santos-Silva A, Rebelo I, et al: Dislipidemia and oxidative stress in mild and in severe psoriasis as a risk for cardiovascular disease. Clin Chim Acta 2001;303:33-39.
9 Fedele S, Sabbah W, Donos N, et al: Common oral mucosal diseases, systemic inflammation and cardiovascular diseases in a large crosssectional US survey. Am Heart J 2011;161: 344-350.

10 Tziomalos K, Athyros VG, Karagiannis A, et al: Endothelial function, arterial stiffness and lipid-lowering drugs. Expert Opin Ther Targets 2007;11:1143-1160.

11 Lang RM, Bierig M, Devereux RB, et al: Recommendations for chamber quantification: a report from the American Society of Echocardiography's Guidelines and Standards Committee and the Chamber Quantification Writing Group, developed in conjunction with the European Association of Echocardiography, a branch of the European Society of Cardiology. J Am Soc Echocardiogr 2005; 18:14401463. 
12 Stefanadis C, Stratos C, Vlachopoulos C, et al: Pressure diameter relation of the human aorta: a new method of determination by the application of a special ultrasonic dimension catheter. Circulation 1995;92:2210-2219.

13 Balta S, Demirkol S, Celik T, et al: Association between coronary artery ectasia and neutrophil-lymphocyte ratio. Angiology 2013;64: 627-632.

14 Wallberg-Jonsson S, Caidahl K, Klintland N, et al: Increased arterial stiffness and indication of endothelial dysfunction in long-standing rheumatoid arthritis. Scand J Rheumatol 2008;37:1-5.

15 Moyssakis I, Gialafos E, Vassiliou V, et al: Aortic stiffness is increased in systemic sclerosis independently of skin involvement. Rheumatology (Oxford) 2005;44:251-254.

16 Booth AD, Wallace S, McEniery CM, et al: Inflammation and arterial stiffness in systemic vasculitis. Arthritis Rheum 2004;50:581-588.

17 Gisondi P, Fantin F, Del Giglio M, et al: Chronic plaque psoriasis is associated with increased arterial stiffness. Dermatology 2009; 218:110-113.

18 Bicer A, Acikel S, Kilic H, et al: Impaired aortic elasticity in patients with psoriasis. Acta Cardiol 2009;64:597-602.
19 Saleh N, Samir N, Megahed H, et al: Homocysteine and other cardiovascular risk factors in patients with lichen planus. J Eur Acad Dermatol Venereol 2014;28:1507-1513.

20 Lou M, Luo P, Tang R, et al: Relationship between neutrophil-lymphocyte ratio and insulin resistance in newly diagnosed type 2 diabetes mellitus patients. BMC Endocr Disord 2015;15:9.

21 Pezelj-Ribaric S, Prso IB, Abram M, et al: Salivary levels of tumor necrosis factor-alpha in oral lichen planus. Mediators Inflamm 2004; 13:131-133.

22 Simark-Mattsson C, Bergenholtz G, Jontell $M$, et al: Distribution of interleukin-2, $-4,-10$, tumor necrosis factor-alpha and transforming growth factor-beta mRNAs in oral lichen planus. Arch Oral Biol 1999;44:499-507.

23 Gratacos J, Collado A, Filella X, et al: Serum cytokines (IL-6, TNF-alpha, IL-1 beta and IFN-gamma) in ankylosing spondylitis: a close correlation between serum IL-6 and disease activity and severity. Br J Rheumatol 1994;33:927-931.

24 Nichols WW, O'Rourke MF: McDonald's Blood Flow in Arteries: Theoretical, Experimental and Clinical Principles, ed 3. London, Oxford University Press, 1990, pp 77-142, 216-269, 283-359, 398-437.
25 Lloyd-Jones D, Adams R, Carnethon M, et al: Heart disease and stroke statistics - 2009 update: a report from the American Heart Association Statistics Committee and Stroke Statistics Subcommittee. Circulation 2009; 119:480-486.

26 Bruch C, Schmermund A, Marin D, et al: TeiIndex in patients with mild to moderate congestive heart failure. Eur Heart J 2000;21: 1888-1895.

27 van Popele NM, Grobbee DE, Bots ML, et al: Association between arterial stiffness and atherosclerosis: The Rotterdam Study. Stroke 2001;32:454-460.

28 Dreiher J, Shapiro J, Cohen AD: Lichen planus and dyslipidaemia: a case control study. Br J Dermatol 2009;161:626-629.

29 Arias-Santiago S, Buendia-Eisman A, Aneiros-Fernandez J, et al: Cardiovascular risk factors in patients with lichen planus. Am J Med 2011;124:543-548.

30 López-Jornet P, Camacho-Alonso F, Rodríguez-Martínes MA: Alterations in serum lipid profile patterns in oral lichen planus: a crosssectional study. Am J Clin Dermatol 2012;13: 399-404. 